\title{
New conditions on fuzzy coupled coincidence fixed point theorem
}

\author{
Shenghua Wang ${ }^{1 *}$, Ting Luo ${ }^{1}$, Ljubomir Ćirić ${ }^{2}$ and Saud M Alsulami ${ }^{3}$
}

"Correspondence:
sheng-huawang@hotmail.com
${ }^{1}$ School of Mathematics and
Physics, North China Electric Power
University, Baoding, 071003, China
Full list of author information is
available at the end of the article

\begin{abstract}
Recently, Choudhury et al. proved a coupled coincidence point theorem in a partial order fuzzy metric space. In this paper, we give a new version of the result of Choudhury et al. by removing some restrictions. In our result, the mappings are not required to be compatible, continuous or commutable, and the t-norm is not required to be of Hadžić-type. Finally, two examples are presented to illustrate the main result of this paper.
\end{abstract}

MSC: $54 \mathrm{E} 70 ; 47 \mathrm{H} 25$

Keywords: fuzzy metric space; contraction mapping; coincidence fixed point; partial order

\section{Introduction}

The concept of fuzzy metric spaces was defined in different ways [1-3]. Grabiec [4] presented a fuzzy version of Banach contraction principle in a fuzzy metric space of Kramosi and Michalek's sense. Fang [5] proved some fixed point theorems in fuzzy metric spaces, which improve, generalize, unify, and extend some main results of Edelstein [6], Istratescu [7], Sehgal and Bharucha-Reid [8].

In order to obtain a Hausdorff topology, George and Veeramani $[9,10]$ modified the concept of fuzzy metric space due to Kramosil and Michalek [11]. Many fixed point theorems in complete fuzzy metric spaces in the sense of George and Veeramani $[9,10]$ have been obtained. For example, Singh and Chauhan [12] proved some common fixed point theorems for four mappings in GV fuzzy metric spaces. Gregori and Sapena [13] proved that each fuzzy contractive mapping has a unique fixed point in a complete GV fuzzy metric space in which fuzzy contractive sequences are Cauchy.

The coupled fixed point theorem and its applications in metric spaces are firstly obtained by Bhaskar and Lakshmikantham [14]. Recently, some authors considered coupled fixed point theorems in fuzzy metric spaces; see [15-18].

In [15], the authors gave the following results.

Theorem 1.1 [15, Theorem 2.5] Let $a * b>$ ab for all $a, b \in[0,1]$ and $(X, M, *)$ be a complete fuzzy metric space such that $M$ has n-property. Let $F: X \times X \rightarrow X$ and $g: X \rightarrow X$ be two functions such that

$$
M(F(x, y), F(u, v), k t) \geq M(g x, g u, t) * M(g y, g v, t)
$$


for all $x, y, u, v \in X$, where $0<k<1, F(X \times X) \subseteq g(X)$ and $g$ is continuous and commutes with $F$. Then there exists a unique $x \in X$ such that $x=g x=F(x, x)$.

Let $\Phi=\left\{\phi: \mathbb{R}^{+} \rightarrow \mathbb{R}^{+}\right\}$, where $\mathbb{R}^{+}=[0,+\infty)$ and each $\phi \in \Phi$ satisfies the following conditions:

$(\phi-1) \quad \phi$ is non-decreasing;

$(\phi-2) \phi$ is upper semicontinuous from the right;

$(\phi-3) \sum_{n=0}^{\infty} \phi^{n}(t)<+\infty$ for all $t>0$ where $\phi^{n+1}(t)=\phi\left(\phi^{n}(t)\right), n \in \mathbb{N}$.

In [16], Hu proved the following result.

Theorem 1.2 [16, Theorem 1] Let $(X, M, *)$ be a complete fuzzy metric space, where $*$ is a continuous t-norm of H-type. Let $F: X \times X \rightarrow X$ and $g: X \rightarrow X$ be two mappings and let there exist $\phi \in \Phi$ such that

$$
M(F(x, y), F(u, v), \phi(t)) \geq M(g x, g u, t) * M(g y, g v, t)
$$

for all $x, y, u, v \in X, t>0$. Suppose that $F(X \times X) \subseteq g(X)$, and $g$ is continuous; $F$ and $g$ are compatible. Then there exists $x \in X$ such that $x=g x=F(x, x)$, that is, $F$ and $g$ have a unique common fixed point in $X$.

Choudhury et al. [17] gave the following coupled coincidence fixed point result in a partial order fuzzy metric space.

Theorem 1.3 [17, Theorem 3.1] Let $(X, M, *)$ be a complete fuzzy metric space with a Hadžić type $t$-norm $M(x, y, t) \rightarrow 1$ as $t \rightarrow \infty$ for all $x, y \in X$. Let $\preceq$ be a partial order defined on $X$. Let $F: X \times X \rightarrow X$ and $g: X \rightarrow X$ be two mappings such that $F$ has mixed $g$-monotone property and satisfies the following conditions:

(i) $F(X \times X) \subseteq g(X)$,

(ii) $g$ is continuous and monotonic increasing,

(iii) $(g, F)$ is a compatible pair,

(iv) $M(F(x, y), F(u, v), k t) \geq \gamma(M(g(x), g(u), t) * M(g(y), g(v), t))$ for all $x, y, u, v \in X, t>0$ with $g(x) \preceq g(u)$ and $g(y) \succeq g(v)$, where $k \in(0,1), \gamma:[0,1] \rightarrow[0,1]$ is a continuous function such that $\gamma(a) * \gamma(a) \geq$ a for each $0 \leq a \leq 1$.

Also suppose that $X$ has the following properties:

(a) if we have a non-decreasing sequence $\left\{x_{n}\right\} \rightarrow x$, then $x_{n} \preceq x$ for all $n \in \mathbb{N} \cup\{0\}$,

(b) if we have a non-increasing sequence $\left\{y_{n}\right\} \rightarrow y$, then $y_{n} \succeq y$ for all $n \in \mathbb{N} \cup\{0\}$.

If there exist $x_{0}, y_{0} \in X$ such that $g\left(x_{0}\right) \preceq F\left(x_{0}, y_{0}\right), g\left(y_{0}\right) \succeq F\left(y_{0}, x_{0}\right)$, and $M\left(g\left(x_{0}\right), F\left(x_{0}, y_{0}\right)\right.$, $t) * M\left(g\left(y_{0}\right), F\left(y_{0}, x_{0}\right), t\right)>0$ for all $t>0$, then there exist $x, y \in X$ such that $g(x)=F(x, y)$ and $g(y)=F(y, x)$, that is, $g$ and $F$ have a coupled coincidence point in $X$.

Wang et al. [18] proved the following coupled fixed point result in a fuzzy metric space.

Theorem 1.4 [18, Theorem 3.1] Let $(X, M, *)$ be a fuzzy metric space under a continuous $t$-norm $*$ of H-type. Let $\phi:(0, \infty) \rightarrow(0, \infty)$ be a function satisfying $\lim _{n \rightarrow \infty} \phi^{n}(t)=0$ for any $t>0$. Let $F: X \times X \rightarrow X$ and $g: X \rightarrow X$ be two mappings with $F(X \times X) \subseteq g(X)$ and 
assume that for any $t>0$,

$$
M(F(x, y), F(u, v), \phi(t)) \geq M(g x, g u, t) * M(g y, g v, t)
$$

for all $x, y, u, v \in X$. Suppose that $F(X \times X)$ is complete and $g$ and $F$ are $w$-compatible, then $g$ and $F$ have a unique common fixed point $x^{*} \in X$, that is, $x^{*}=g\left(x^{*}\right)=F\left(x^{*}, x^{*}\right)$.

In this paper, by modifying the conditions on the result of Choudhury et al. [17], we give a new coupled coincidence fixed point theorem in partial order fuzzy metric spaces. In our result, we do not require that the $t$-norm is of Hadžić-type [19], the mappings are compatible [16], commutable, continuous or monotonic increasing. Our proof method is different from the one of Choudhury et al. Finally, some examples are presented to illustrate our result.

\section{Preliminaries}

Definition 2.1 [9] A binary operation $*:[0,1] \times[0,1] \rightarrow[0,1]$ is continuous $t$-norm if $*$ satisfies the following conditions:

(1) $*$ is associative and commutative,

(2) $*$ is continuous,

(3) $a * 1=a$ for all $a \in[0,1]$

(4) $a * b \leq c * d$ whenever $a \leq c$ and $b \leq d$ for all $a, b, c, d \in[0,1]$.

Typical examples of the continuous $t$-norm are $a *_{1} b=a b$ and $a *_{2} b=\min \{a, b\}$ for all $a, b \in[0,1]$.

A $t$-norm $*$ is said to be positive if $a * b>0$ for all $a, b \in(0,1]$. Obviously, $*_{1}$ and $*_{2}$ are positive $t$-norms.

Definition 2.2 [9] The 3-tuple $(X, M, *)$ is called a fuzzy metric space if $X$ is an arbitrary non-empty set, $*$ is a continuous $t$-norm and $M$ is a fuzzy set on $X^{2} \times(0, \infty)$ satisfying the following conditions for each $x, y, z \in X$ and $t, s>0$ :

$(\mathrm{GV}-1) \quad M(x, y, t)>0$,

(GV-2) $M(x, y, t)=1$ if and only if $x=y$,

$(\mathrm{GV}-3) \quad M(x, y, t)=M(y, x, t)$

$(\mathrm{KM}-4) M(x, y, \cdot):(0, \infty) \rightarrow[0,1]$ is continuous,

$(\mathrm{KM}-5) \quad M(x, y, t+s) \geq M(x, z, t) * M(y, z, s)$.

Lemma 2.1 [4] Let $(X, M, *)$ be a fuzzy metric space. Then $M(x, y, *)$ is non-decreasing for all $x, y \in X$.

Lemma 2.2 [20] Let $(X, M, *)$ be a fuzzy metric space. Then $M$ is a continuous function on $X^{2} \times(0, \infty)$.

Definition 2.3 [9] Let $(X, M, *)$ be a fuzzy metric space. A sequence $\left\{x_{n}\right\}$ in $X$ is called an $M$-Cauchy sequence, if for each $\epsilon \in(0,1)$ and $t>0$ there is $n_{0} \in \mathbb{N}$ such that $M\left(x_{n}, x_{m}, t\right)>$ $1-\epsilon$ for all $m, n \geq n_{0}$. The fuzzy metric space $(X, M, *)$ is called $M$-complete if every $M$ Cauchy sequence is convergent. 
Let $(X, \preceq)$ be a partially ordered set and $F$ be a mapping from $X$ to itself. A sequence $\left\{x_{n}\right\}$ in $X$ is said to be non-decreasing if for each $n \in \mathbb{N}, x_{n} \preceq x_{n+1}$. A mapping $g: X \rightarrow X$ is called monotonic increasing if for all $x, y \in X$ with $x \preceq y, g(x) \preceq g(y)$.

Definition 2.4 [21] Let $(X, \preceq)$ be a partially ordered set and $F: X \times X \rightarrow X$ and $g: X \rightarrow X$ be two mappings. The mapping $F$ is said to have the mixed $g$-monotone property if for all $x_{1}, x_{2} \in X, g\left(x_{1}\right) \preceq g\left(x_{2}\right)$ implies $F\left(x_{1}, y\right) \preceq F\left(x_{2}, y\right)$ for all $y \in X$, and for all $y_{1}, y_{2} \in X$, $g\left(y_{1}\right) \preceq g\left(y_{2}\right)$ implies $F\left(x, y_{1}\right) \succeq F\left(x, y_{2}\right)$ for all $x \in X$.

Definition 2.5 [14] An element $(x, y) \in X \times X$ is called a coupled coincidence point of the mappings $F: X \times X \rightarrow X$ and $g: X \rightarrow X$ if

$$
F(x, y)=g(x), \quad F(y, x)=g(y) .
$$

Here $(g x, g y)$ is called a coupled point of coincidence.

\section{Main results}

Lemma 3.1 Let $\gamma:[0,1] \rightarrow[0,1]$ be a left continuous function and $*$ be a continuous $t$ norm. Assume that $\gamma(a) * \gamma(a)>$ a for all $a \in(0,1)$. Then $\gamma(1)=1$.

Proof Let $\left\{a_{n}\right\} \subseteq(0,1)$ be a non-decreasing sequence with $\lim _{n \rightarrow \infty} a_{n}=1$. By hypothesis we have

$$
\gamma\left(a_{n}\right) * \gamma\left(a_{n}\right)>a_{n}, \quad n \in \mathbb{N} .
$$

Since $\gamma$ is left continuous and $*$ is continuous, we get

$$
\gamma(1) * \gamma(1) \geq 1,
$$

which implies that $\gamma(1) * \gamma(1)=1$. Since $\gamma(1) \geq \gamma(1) * \gamma(1)$, one has $\gamma(1)=1$. This completes the proof.

Theorem 3.1 Let $(X, M, *)$ be a fuzzy metric space with a continuous and positive $t$-norm. Let $\preceq$ be a partial order defined on $X$. Let $\phi:(0, \infty) \rightarrow(0, \infty)$ be a function satisfying $\phi(t) \leq$ $t$ for all $t>0$ and let $\gamma:[0,1] \rightarrow[0,1]$ be a left continuous and increasing function satisfying $\gamma(a) * \gamma(a)>a$ for all $a \in(0,1)$. Let $F: X \times X \rightarrow X$ and $g: X \rightarrow X$ be two mappings such that $F$ has the mixed $g$-monotone property and assume that $g(X)$ is complete. Suppose that the following conditions hold:

(i) $F(X \times X) \subseteq g(X)$,

(ii) we have

$$
M(F(x, y), F(u, v), \phi(t)) \geq \gamma(M(g(x), g(u), t) * M(g(y), g(v), t)),
$$

for all $x, y, u, v \in X, t>0$ with $g(x) \preceq g(u)$ and $g(y) \succeq g(v)$,

(iii) if a non-decreasing sequence $\left\{x_{n}\right\} \rightarrow x$, then $x_{n} \preceq x$ for all $n \in \mathbb{N} \cup\{0\}$,

(iv) if a non-increasing sequence $\left\{y_{n}\right\} \rightarrow y$, then $y_{n} \succeq y$ for all $n \in \mathbb{N} \cup\{0\}$. 
If there exist $x_{0}, y_{0} \in X$ such that $g\left(x_{0}\right) \preceq F\left(x_{0}, y_{0}\right), g\left(y_{0}\right) \succeq F\left(y_{0}, x_{0}\right)$ and $M\left(g\left(x_{0}\right), F\left(x_{0}, y_{0}\right)\right.$, $t) * M\left(g\left(y_{0}\right), F\left(y_{0}, x_{0}\right), t\right)>0$ for all $t>0$, then there exist $x^{*}, y^{*} \in X$ such that $g\left(x^{*}\right)=F\left(x^{*}, y^{*}\right)$ and $g\left(y^{*}\right)=F\left(y^{*}, x^{*}\right)$.

Proof Let $x_{0}, y_{0} \in X$ such that $g\left(x_{0}\right) \preceq F\left(x_{0}, y_{0}\right)$ and $F\left(y_{0}, x_{0}\right) \preceq g\left(y_{0}\right)$. Define the sequences $\left\{x_{n}\right\}$ and $\left\{y_{n}\right\}$ in $X$ by

$$
g\left(x_{n+1}\right)=F\left(x_{n}, y_{n}\right) \quad \text { and } \quad g\left(y_{n+1}\right)=F\left(y_{n}, x_{n}\right), \quad \text { for all } n \in \mathbb{N} \cup\{0\} \text {. }
$$

Along the lines of the proof of [17], we see that

$$
g\left(x_{n}\right) \preceq g\left(x_{n+1}\right) \quad \text { and } \quad g\left(y_{n}\right) \succeq g\left(y_{n+1}\right), \quad \text { for all } n \in \mathbb{N} \cup\{0\} .
$$

By (3.1) and (3.2) we have

$$
\begin{aligned}
M\left(g\left(x_{1}\right), g\left(x_{2}\right), t\right) & \geq M\left(g\left(x_{1}\right), g\left(x_{2}\right), \phi(t)\right) \\
& =M\left(F\left(x_{0}, y_{0}\right), F\left(x_{1}, y_{1}\right), \phi(t)\right) \\
& \geq \gamma\left(M\left(g\left(x_{0}\right), g\left(x_{1}\right), t\right) * M\left(g\left(y_{0}\right), g\left(y_{1}\right), t\right)\right) \\
& >M\left(g\left(x_{0}\right), g\left(x_{1}\right), t\right) * M\left(g\left(y_{0}\right), g\left(y_{1}\right), t\right)>0, \quad \forall t>0,
\end{aligned}
$$

and

$$
\begin{aligned}
M\left(g\left(y_{1}\right), g\left(y_{2}\right), t\right) & \geq M\left(g\left(y_{1}\right), g\left(y_{2}\right), \phi(t)\right) \\
& =M\left(F\left(y_{0}, x_{0}\right), F\left(y_{1}, x_{1}\right), \phi(t)\right) \\
& \geq \gamma\left(M\left(g\left(y_{0}\right), g\left(y_{1}\right), t\right) * M\left(g\left(x_{0}\right), g\left(x_{1}\right), t\right)\right) \\
& >M\left(g\left(y_{0}\right), g\left(y_{1}\right), t\right) * M\left(g\left(x_{0}\right), g\left(x_{1}\right), t\right)>0, \quad \forall t>0 .
\end{aligned}
$$

Since $*$ is positive, we have

$$
M\left(g\left(x_{1}\right), g\left(x_{2}\right), t\right) * M\left(g\left(y_{1}\right), g\left(y_{2}\right), t\right)>0, \quad \forall t>0 .
$$

Repeating the process (3.3) and (3.4), we get

$$
M\left(g\left(x_{2}\right), g\left(x_{3}\right), t\right)>0 \quad \text { and } \quad M\left(g\left(y_{2}\right), g\left(y_{3}\right), t\right)>0, \quad \forall t>0,
$$

and further we have

$$
M\left(g\left(x_{2}\right), g\left(x_{3}\right), t\right) * M\left(g\left(y_{2}\right), g\left(y_{3}\right), t\right)>0, \quad \forall t>0 .
$$

Continuing the above process, we get, for each $n \in \mathbb{N}$,

$$
M\left(g\left(x_{n}\right), g\left(x_{n+1}\right), t\right)>0, \quad \forall t>0,
$$

and

$$
M\left(g\left(y_{n}\right), g\left(y_{n+1}\right), t\right)>0, \quad \forall t>0 .
$$


Since $*$ is positive, one has

$$
M\left(g\left(x_{n}\right), g\left(x_{n+1}\right), t\right) * M\left(g\left(y_{n}\right), g\left(y_{n+1}\right), t\right)>0, \quad \forall n \in \mathbb{N}, \forall t>0
$$

Now we prove by induction that, for each $n \in \mathbb{N}$ and $k \in \mathbb{N}$ with $k \geq n$, one has

$$
M\left(g\left(x_{n}\right), g\left(x_{k}\right), t\right) * M\left(g\left(y_{n}\right), g\left(y_{k}\right), t\right)>0, \quad \forall t>0
$$

Obviously (3.5) holds for $k=n$. Assume that (3.5) holds for some $k \in \mathbb{N}$ with $k>n$. Then we have

$$
M\left(g\left(x_{n}\right), g\left(x_{k+1}\right), t\right) \geq M\left(g\left(x_{n}\right), g\left(x_{k}\right), t / 2\right) * M\left(g\left(x_{k}\right), g\left(x_{k+1}\right), t / 2\right) .
$$

Since $M\left(g\left(x_{n}\right), g\left(x_{k}\right), t / 2\right)>0, M\left(g\left(x_{k}\right), g\left(x_{k+1}\right), t / 2\right)>0$, and $*$ is positive, we have

$$
M\left(g\left(x_{n}\right), g\left(x_{k+1}\right), t\right)>0, \quad \forall t>0 .
$$

Similarly, we have

$$
M\left(g\left(y_{n}\right), g\left(y_{k+1}\right), t\right)>0, \quad \forall t>0 .
$$

Therefore, (3.5) holds for all $k \in \mathbb{N}$ with $k \geq n$.

Now we use the method of Wang [22] to show that both $\left\{g\left(x_{n}\right)\right\}$ and $\left\{g\left(y_{n}\right)\right\}$ are Cauchy sequences. Fix $t>0$. Let

$$
a_{n}=\inf _{k \geq n} M\left(g\left(x_{n}\right), g\left(x_{k}\right), t\right) * M\left(g\left(y_{n}\right), g\left(y_{k}\right), t\right) .
$$

For $k \geq n+1$, by (3.1) and (3.2) we have

$$
\begin{aligned}
M\left(g\left(x_{n+1}\right), g\left(x_{k}\right), t\right) & \geq M\left(g\left(x_{n+1}\right), g\left(x_{k}\right), \phi(t)\right) \\
& \geq \gamma\left(M\left(g\left(x_{n}\right), g\left(x_{k-1}\right), t\right) * M\left(g\left(y_{n}\right), g\left(y_{k-1}\right), t\right)\right) .
\end{aligned}
$$

Similarly,

$$
M\left(g\left(y_{n+1}\right), g\left(y_{k}\right), t\right) \geq \gamma\left(M\left(g\left(x_{n}\right), g\left(x_{k-1}\right), t\right) * M\left(g\left(y_{n}\right), g\left(y_{k-1}\right), t\right)\right) .
$$

So, by (3.5) and the hypothesis we have

$$
\begin{aligned}
& M\left(g\left(x_{n+1}\right), g\left(x_{k}\right), t\right) * M\left(g\left(y_{n+1}\right), g\left(y_{k}\right), t\right) \\
& \quad \geq *^{2}\left(\gamma\left(M\left(g\left(x_{n}\right), g\left(x_{k-1}\right), t\right) * M\left(g\left(y_{n}\right), g\left(y_{k-1}\right), t\right)\right)\right) \\
& \quad \geq M\left(g\left(x_{n}\right), g\left(x_{k-1}\right), t\right) * M\left(g\left(y_{n}\right), g\left(y_{k-1}\right), t\right)>0,
\end{aligned}
$$

which implies that

$$
a_{n+1} \geq a_{n}>0 \text {. }
$$


Since $\left\{a_{n}\right\}$ is bounded, there exists $a \in(0,1]$ such that $\lim _{n \rightarrow \infty} a_{n}=a$. Assume that $a<1$. Since $\gamma$ is increasing, we have

$$
\begin{aligned}
& *^{2}\left(\gamma\left(M\left(g\left(x_{n}\right), g\left(x_{k-1}\right), t\right) * M\left(g\left(y_{n}\right), g\left(y_{k-1}\right), t\right)\right)\right) \\
& \quad \geq *^{2}\left(\gamma\left(\inf _{k \geq n+1}\left(M\left(g\left(x_{n}\right), g\left(x_{k-1}\right), t\right) * M\left(g\left(y_{n}\right), g\left(y_{k-1}\right), t\right)\right)\right)\right)
\end{aligned}
$$

and further

$$
\begin{aligned}
& \inf _{k \geq n+1} *^{2}\left(\gamma\left(\left(M\left(g\left(x_{n}\right), g\left(x_{k-1}\right), t\right) * M\left(g\left(y_{n}\right), g\left(y_{k-1}\right), t\right)\right)\right)\right) \\
& \quad \geq *^{2}\left(\gamma\left(\inf _{k \geq n+1}\left(M\left(g\left(x_{n}\right), g\left(x_{k-1}\right), t\right) * M\left(g\left(y_{n}\right), g\left(y_{k-1}\right), t\right)\right)\right)\right) .
\end{aligned}
$$

From (3.6) and (3.7) it follows that

$$
\begin{aligned}
& \inf _{k \geq n+1}\left(M\left(g\left(x_{n+1}\right), g\left(x_{k}\right), t\right) * M\left(g\left(y_{n+1}\right), g\left(y_{k}\right), t\right)\right) \\
& \quad \geq *^{2}\left(\gamma\left(\inf _{k \geq n+1}\left(M\left(g\left(x_{n}\right), g\left(x_{k-1}\right), t\right) * M\left(g\left(y_{n}\right), g\left(y_{k-1}\right), t\right)\right)\right)\right),
\end{aligned}
$$

i.e.,

$$
a_{n+1} \geq \gamma\left(a_{n}\right) * \gamma\left(a_{n}\right), \quad \forall n \in \mathbb{N} .
$$

Since $\gamma$ is left continuous, by hypothesis we get

$$
a \geq \gamma(a) * \gamma(a)>a .
$$

This is a contradiction. So $a=1$.

For any given $\epsilon>0$, there exists $n_{0} \in \mathbb{N}$ such that

$$
1-a_{n}<\epsilon \text { for all } n \geq n_{0} .
$$

Thus for each $k \geq n \geq n_{0}$,

$$
M\left(g\left(x_{n}\right), g\left(x_{k}\right), t\right) * M\left(g\left(y_{n}\right), g\left(y_{k}\right), t\right)>1-\epsilon,
$$

which implies that

$$
\min \left\{M\left(g\left(x_{n}\right), g\left(x_{k}\right), t\right), M\left(g\left(y_{n}\right), g\left(y_{k}\right), t\right)\right\}>1-\epsilon .
$$

It follows that both $\left\{g\left(x_{n}\right)\right\}$ and $\left\{g\left(y_{n}\right)\right\}$ are Cauchy sequences. Since $g(X)$ is complete, there exist $x^{*}, y^{*} \in X$ such that $g\left(x_{n}\right) \rightarrow g\left(x^{*}\right)$ and $g\left(y_{n}\right) \rightarrow g\left(y^{*}\right)$ as $n \rightarrow \infty$.

By hypothesis, we have

$$
g\left(x_{n}\right) \preceq g\left(x^{*}\right) \quad \text { and } \quad g\left(y_{n}\right) \succeq g\left(y^{*}\right), \quad n \in \mathbb{N} .
$$


Now, for all $t>0$, by (3.1) and (3.8) we have

$$
\begin{aligned}
M\left(F\left(x^{*}, y^{*}\right), g\left(x^{*}\right), t\right) \geq & M\left(F\left(x^{*}, y^{*}\right), F\left(x_{n}, y_{n}\right), t / 2\right) * M\left(F\left(x_{n}, y_{n}\right), g\left(x^{*}\right), t / 2\right) \\
\geq & M\left(F\left(x^{*}, y^{*}\right), F\left(x_{n}, y_{n}\right), \phi(t / 2)\right) * M\left(F\left(x_{n}, y_{n}\right), g\left(x^{*}\right), \phi(t / 2)\right) \\
\geq & \gamma\left(M\left(g\left(x^{*}\right), g\left(x_{n}\right), t / 2\right) * M\left(g\left(y^{*}\right), g\left(y_{n}\right), t / 2\right)\right) \\
& * M\left(F\left(x_{n}, y_{n}\right), g\left(x^{*}\right), \phi(t / 2)\right) .
\end{aligned}
$$

Since $\gamma$ is left continuous and $*$ is continuous, letting $n \rightarrow \infty$ in (3.9), we get

$$
\begin{aligned}
M\left(F\left(x^{*}, y^{*}\right), g\left(x^{*}\right), t\right) \geq & \lim _{n \rightarrow \infty}\left[\gamma\left(M\left(g\left(x^{*}\right), g\left(x_{n}\right), t / 2\right) * M\left(g\left(y^{*}\right), g\left(y_{n}\right), t / 2\right)\right)\right. \\
& \left.* M\left(F\left(x_{n}, y_{n}\right), g\left(x^{*}\right), \phi(t / 2)\right)\right] \\
& =\gamma(1 * 1) * 1=1, \quad \forall t>0 .
\end{aligned}
$$

It follows that $F\left(x^{*}, y^{*}\right)=g\left(x^{*}\right)$. Similarly, we can prove that $F\left(y^{*}, x^{*}\right)=g\left(y^{*}\right)$. This completes the proof.

If $\phi(t)=t$ for all $t>0$ in Theorem 3.1, we get the following corollary.

Corollary 3.1 Let $(X, M, *)$ be a fuzzy metric space with a positive $t$-norm. Let $\preceq$ be a partial order defined on $X$. Let $\gamma:[0,1] \rightarrow[0,1]$ be a left continuous and increasing function satisfying $\gamma(a) * \gamma(a)>a$ for all $a \in(0,1)$. Let $F: X \times X \rightarrow X$ and $g: X \rightarrow X$ be two mappings such that $F$ has mixed $g$-monotone property and assume that $g(X)$ is complete. Suppose that the following conditions hold:

(i) $F(X \times X) \subseteq g(X)$.

(ii) We have

$$
M(F(x, y), F(u, v), t) \geq \gamma(M(g(x), g(u), t) * M(g(y), g(v), t)),
$$

for all $x, y, u, v \in X, t>0$ with $g(x) \preceq g(u)$ and $g(y) \succeq g(v)$.

(iii) If we have a non-decreasing sequence $\left\{x_{n}\right\} \rightarrow x$, then $x_{n} \preceq x$ for all $n \in \mathbb{N} \cup\{0\}$.

(iv) If we have a non-increasing sequence $\left\{y_{n}\right\} \rightarrow y$, then $y_{n} \succeq y$ for all $n \in \mathbb{N} \cup\{0\}$.

If there exist $x_{0}, y_{0} \in X$ such that $g\left(x_{0}\right) \preceq F\left(x_{0}, y_{0}\right), g\left(y_{0}\right) \succeq F\left(y_{0}, x_{0}\right)$ and $M\left(g\left(x_{0}\right), F\left(x_{0}, y_{0}\right)\right.$, $t) * M\left(g\left(y_{0}\right), F\left(y_{0}, x_{0}\right), t\right)>0$ for all $t>0$, then there exist $x^{*}, y^{*} \in X$ such that $g\left(x^{*}\right)=F\left(x^{*}, y^{*}\right)$ and $g\left(y^{*}\right)=F\left(y^{*}, x^{*}\right)$.

Letting $g(x)=x$ for all $x \in X$ in Theorem 3.1 and Corollary 3.1, we get the following corollaries.

Corollary 3.2 Let $(X, M, *)$ be a complete fuzzy metric space with a positive t-norm. Let $\preceq$ be a partial order defined on $X$. Let $\phi:(0, \infty) \rightarrow(0, \infty)$ be a function satisfying $\phi(t) \leq t$ for all $t>0$ and let $\gamma:[0,1] \rightarrow[0,1]$ be a left continuous and increasing function satisfying $\gamma(a) * \gamma(a)>a$ for all $a \in(0,1)$. Let $F: X \times X \rightarrow X$ and assume $F$ has mixed monotone property. Suppose that the following conditions hold: 
(i) We have

$$
M(F(x, y), F(u, v), \phi(t)) \geq \gamma(M(x, u, t) * M(y, v, t))
$$

for all $x, y, u, v \in X, t>0$ with $x \preceq u$ and $y \succeq v$.

(ii) If we have a non-decreasing sequence $\left\{x_{n}\right\} \rightarrow x$, then $x_{n} \preceq x$ for all $n \in \mathbb{N} \cup\{0\}$.

(iii) If we have a non-increasing sequence $\left\{y_{n}\right\} \rightarrow y$, then $y_{n} \succeq y$ for all $n \in \mathbb{N} \cup\{0\}$.

If there exist $x_{0}, y_{0} \in X$ such that $x_{0} \preceq F\left(x_{0}, y_{0}\right), y_{0} \succeq F\left(y_{0}, x_{0}\right)$ and $M\left(x_{0}, F\left(x_{0}, y_{0}\right), t\right) *$ $M\left(y_{0}, F\left(y_{0}, x_{0}\right), t\right)>0$ for all $t>0$, then there exist $x^{*}, y^{*} \in X$ such that $x^{*}=F\left(x^{*}, y^{*}\right)$ and $y^{*}=F\left(y^{*}, x^{*}\right)$.

Corollary 3.3 Let $(X, M, *)$ be a complete fuzzy metric space with a positive $t$-norm. Let $\preceq$ be a partial order defined on $X$. Let $\gamma:[0,1] \rightarrow[0,1]$ be a left continuous and increasing function satisfying $\gamma(a) * \gamma(a)>a$ for all $a \in(0,1)$. Let $F: X \times X \rightarrow X$ and assume $F$ has mixed monotone property. Suppose that the following conditions hold:

(i) We have

$$
M(F(x, y), F(u, v), t) \geq \gamma(M(x, u, t) * M(y, v, t))
$$

for all $x, y, u, v \in X, t>0$ with $x \preceq u$ and $y \succeq v$.

(ii) If we have a non-decreasing sequence $\left\{x_{n}\right\} \rightarrow x$, then $x_{n} \preceq x$ for all $n \in \mathbb{N} \cup\{0\}$.

(iii) If we have a non-increasing sequence $\left\{y_{n}\right\} \rightarrow y$, then $y_{n} \succeq y$ for all $n \in \mathbb{N} \cup\{0\}$.

If there exist $x_{0}, y_{0} \in X$ such that $x_{0} \preceq F\left(x_{0}, y_{0}\right), y_{0} \succeq F\left(y_{0}, x_{0}\right)$, and $M\left(x_{0}, F\left(x_{0}, y_{0}\right), t\right) *$ $M\left(y_{0}, F\left(y_{0}, x_{0}\right), t\right)>0$ for all $t>0$, then there exist $x^{*}, y^{*} \in X$ such that $x^{*}=F\left(x^{*}, y^{*}\right)$ and $y^{*}=F\left(y^{*}, x^{*}\right)$.

First, we illustrate Theorem 3.1 by modifying [17, Example 3.4] as follows.

Example 3.1 Let $(X, \preceq)$ is the partially ordered set with $X=[0,1]$ and the natural ordering $\leq$ of the real numbers as the partial ordering $\preceq$. Define $M: X^{2} \times(0, \infty)$ by

$$
M(x, y, t)=e^{-|x-y| / t}, \quad \forall x, y \in X, \forall t>0 .
$$

Let $a * b=a b$ for all $a, b \in[0,1]$. Then $(X, M, *)$ is a (complete) fuzzy metric space.

Let $\psi(t)=t$ for all $t>0$ and $\gamma(s)=s^{\frac{1}{3}}$ for all $s \in[0,1]$. It is easy to see that $\gamma(s) * \gamma(s)>s$ for all $s \in(0,1)$.

Define the mappings $g: X \rightarrow X$ by

$$
g(x)=x^{2}, \quad \forall x \in X
$$

and $F: X \times X \rightarrow X$ by

$$
F(x, y)=\frac{x^{2}-y^{2}}{3}+\frac{2}{3}, \quad \forall x, y \in X
$$

Then $F(X \times X) \subseteq g(X), F$ satisfies the mixed $g$-monotone property; see [17, Example 3.4]. Obviously $g(X)$ is complete. 
Let $x_{0}=0$ and $y_{0}=1$, then $g\left(x_{0}\right) \leq F\left(x_{0}, y_{0}\right)$ and $g\left(y_{0}\right) \geq F\left(y_{0}, x_{0}\right)$; see [17, Example 3.4]. Moreover, $M\left(g\left(x_{0}\right), F\left(x_{0}, y_{0}\right), t\right) * M\left(g\left(y_{0}\right), F\left(y_{0}, x_{0}\right), t\right)>0$ for all $t>0$.

Next we show that for all $t>0$ and all $x, y, u, v \in X$ with $g(x) \leq g(u)$ and $g(y) \geq g(v)$, i.e., $x \leq u$ and $y \geq v$, one has

$$
M(F(x, y), F(u, v), t) \geq(M(g(x), g(u), t) M(g(y), g(v), t))^{\frac{1}{3}} .
$$

We prove the above inequality by a contradiction. Assume

$$
M(F(x, y), F(u, v), t)<(M(g(x), g(u), t) M(g(y), g(v), t))^{\frac{1}{3}} .
$$

Then

$$
e^{-\left|\left(x^{2}-y^{2}\right) / 3-\left(u^{2}-v^{2}\right) / 3\right| / t}<e^{-\left(\left|x^{2}-u^{2}\right|+\left|y^{2}-v^{2}\right|\right) / 3 t},
$$

i.e.,

$$
\left|\left(x^{2}-u^{2}\right)-\left(y^{2}-v^{2}\right)\right|>\left|x^{2}-u^{2}\right|+\left|y^{2}-v^{2}\right| .
$$

This is a contradiction. Thus, (3.10) holds. Therefore, all the conditions of Theorem 3.1 are satisfied. Then by Theorem 3.1 we conclude that there exist $x^{*}, y^{*}$ such that $g\left(x^{*}\right)=F\left(x^{*}, y^{*}\right)$ and $g\left(y^{*}\right)=F\left(y^{*}, x^{*}\right)$. It is easy to see that $\left(x^{*}, y^{*}\right)=\left(\sqrt{\frac{2}{3}}, \sqrt{\frac{2}{3}}\right)$, as desired.

Example 3.2 Let $(X, \preceq)$ is the partially ordered set with $X=[0,1) \cup\{2\}$ and the natural ordering $\leq$ of the real numbers as the partial ordering $\preceq$. Define a mapping $M: X^{2} \times$ $(0, \infty)$ by $M(x, x, t)=e^{-|x-y|}$ for all $x, y \in X$ and $t>0$. Let $a * b=a b$ for all $a, b \in[0,1]$. Then $(X, M, *)$ is a fuzzy metric space but not complete.

Define the mappings $g: X \rightarrow X$ and $F: X \times X \rightarrow X$ by

$$
g(x)= \begin{cases}\frac{1}{2}(1-x), & \text { if } 0 \leq x<1 \\ 0, & \text { if } x=2,\end{cases}
$$

and $F(x, y)=\frac{y-x}{16}+\frac{1}{8}$ for all $x, y \in X$. Then $F(X \times X) \subseteq g(X), F$ satisfies the mixed $g$ monotone property, and $g(X)$ is complete. Take $\left(x_{0}, y_{0}\right)=\left(\frac{23}{28}, \frac{1}{4}\right)$. By a simple calculation we see that $g\left(x_{0}\right) \leq F\left(x_{0}, y_{0}\right)$ and $g\left(y_{0}\right) \geq F\left(y_{0}, x_{0}\right)$. Moreover, $M\left(g\left(x_{0}\right), F\left(x_{0}, y_{0}\right), t\right) *$ $M\left(g\left(y_{0}\right), F\left(y_{0}, x_{0}\right), t\right)>0$ for all $t>0$.

Let $\phi(t)=t$ for all $t>0$. Let $\gamma$ be a function from $[0,1]$ to $[0,1]$ defined by

$$
\gamma(s)= \begin{cases}\sqrt[3]{s}, & \text { if } 0 \leq s \leq \frac{1}{2} \\ \sqrt[4]{s}, & \text { if } \frac{1}{2}<s \leq 1\end{cases}
$$

Obviously, $\gamma$ is left continuous and increasing, and $\gamma(s) * \gamma(s)>s$ for all $s \in(0,1)$. 
Let $t>0$ and $x, y, u, v \in X$ with $g(x) \leq g(u)$ and $g(y) \geq g(v)$, i.e., $u \leq x$ and $y \leq v$, since

$$
\begin{aligned}
M(F(x, y), F(u, v), \phi(t)) & =e^{-|F(x, y)-F(u, v)|}=e^{-\left|\frac{x-y}{16}-\frac{u-v}{16}\right|} \\
& \geq \max \left\{e^{-\frac{|x-y|+|y-v|}{6}}, e^{-\frac{|x-y|+|y-v|}{8}}\right\} \\
& \geq \gamma(M(g(x), g(u), t) * M(g(y), g(v), t)) .
\end{aligned}
$$

Hence (3.1) is satisfied. Therefore, all the conditions of Theorem 3.1 are satisfied. Then by Theorem 3.1 $F$ and $g$ have a coincidence point. It is easy to check that $\left(x^{*}, y^{*}\right)=\left(\frac{3}{4}, \frac{3}{4}\right)$.

The above two examples cannot be applied to [17, Theorem 3.1], since $*$ is not of Hadžićtype, or $g$ is not monotonic increasing or continuous, or $M(x, y, t) \nrightarrow 1$ as $t \rightarrow \infty$ for all $x, y \in X$.

\section{Conclusion}

In this paper, we prove a new coupled coincidence fixed point result in a partial order fuzzy metric space in which some restrictions required in [17, Theorem 3.1] are removed, such that the conditions required in our result are fewer than the ones required in [17, Theorem 3.1]. The purpose of this paper is to give some new conditions on the coupled coincidence fixed point theorem. Our result is not an improvement of [17, Theorem 3.1], since we add some other restrictions such as requiring that the function $\gamma$ is increasing and $M\left(g\left(x_{0}\right), F\left(x_{0}, y_{0}\right), t\right) * M\left(g\left(y_{0}\right), F\left(y_{0}, x_{0}\right), t\right)>0$ for all $t>0$. As pointed out in the conclusion part of [17], it still is an interesting open problem to find simpler or fewer conditions on the coupled coincidence fixed point theorem in a fuzzy metric space.

\section{Competing interests}

The authors declare that they have no competing interests.

\section{Authors' contributions}

All authors read and approved the final manuscript.

\section{Author details}

'School of Mathematics and Physics, North China Electric Power University, Baoding, 071003, China. ${ }^{2}$ Faculty of Mechanical Engineering, University of Belgrade, Kraljice Marije 16, Belgrade, 11000, Serbia. ${ }^{3}$ Department of Mathematics, King Abdulaziz University, Jeddah, 21323, Saudi Arabia.

\section{Acknowledgements}

This work is supported by the Fundamental Research Funds for the Central Universities (Grant Numbers: 13MS109, 2014ZD44) and funded by the Deanship of Scientific Research (DSR), King Abdulaziz University, Jeddah. The authors Alsulami and Ćirić, therefore, acknowledge with thanks the DSR financial support.

Received: 11 February 2014 Accepted: 13 June 2014 Published: 22 Jul 2014

\section{References}

1. Deng, ZK: Fuzzy pseudo metric spaces. J. Math. Anal. Appl. 86, 74-95 (1982)

2. Erceg, MA: Metric spaces in fuzzy set theory. J. Math. Anal. Appl. 69, 205-230 (1979)

3. Kaleva, O, Seikkala, S: On fuzzy metric spaces. Fuzzy Sets Syst. 12, 215-229 (1984)

4. Grabiec, M: Fixed points in fuzzy metric spaces. Fuzzy Sets Syst. 27, 385-389 (1988)

5. Fang, JX: On fixed point theorems in fuzzy metric spaces. Fuzzy Sets Syst. 46, 107-113 (1992)

6. Edelstein, M: On fixed and periodic points under contraction mappings. J. Lond. Math. Soc. 37, 74-79 (1962)

7. Istratescu, I: A fixed point theorem for mappings with a probabilistic contractive iterate. Rev. Roum. Math. Pures Appl. 26, 431-435 (1981)

8. Sehgal, VM, Bharucha-Reid, AT: Fixed points of contraction mappings on PM-spaces. Math. Syst. Theory 6, 97-100 (1972)

9. George, A, Veeramani, P: On some results in fuzzy metric spaces. Fuzzy Sets Syst. 64, 395-399 (1994)

10. George, A, Veeramani, P: On some results of analysis for fuzzy metric spaces. Fuzzy Sets Syst. 90, 365-368 (1997)

11. Kramosil, O, Michalek, J: Fuzzy metric and statistical metric space. Kybernetika 11, 326-334 (1975) 
12. Singh, B, Chauhan, MS: Common fixed points of compatible maps in fuzzy metric spaces. Fuzzy Sets Syst. 115 , 471-475 (2000)

13. Gregori, V, Sapena, A: On fixed-point theorems in fuzzy metric spaces. Fuzzy Sets Syst. 125, 245-252 (2002)

14. Bhashkar, TG, Lakshmikantham, V: Fixed point theorems in partially ordered metric spaces and applications. Nonlinear Anal. 65, 1379-1393 (2006)

15. Sedghi, S, Altun, I, Shobe, N: Coupled fixed point theorems for contractions in fuzzy metric spaces. Nonlinear Anal. 72, 1298-1304 (2010)

16. $\mathrm{Hu}, \mathrm{XQ}$ : Common coupled fixed point theorems for contractive mappings in fuzzy metric spaces. Fixed Point Theory Appl. 2011, Article ID 363716 (2011)

17. Choudhury, BS, Das, K, Das, P: Coupled coincidence point results for compatible mappings in partially ordered fuzzy metric spaces. Fuzzy Sets Syst. 222, 84-97 (2013)

18. Wang, SH, Alsulami, SM, Ćirić, L: Common fixed point theorems for nonlinear contractive mappings in fuzzy metric spaces. Fixed Point Theory Appl. 2013, 191 (2013)

19. Hadžić, O, Pap, E: Fixed Point Theory in Probabilistic Metric Spaces. Mathematics and Its Application, vol. 536. Kluwer Academic, Dordrecht (2001)

20. López, J, Romaguera, S: The Hausdorff fuzzy metric on compact sets. Fuzzy Sets Syst. 147, 273-283 (2004)

21. Lakahmikantham, $\vee$, Ćirić, L: Coupled fixed point theorems for nonlinear contractions in partially ordered metric spaces. Nonlinear Anal. 70, 4341-4349 (2009)

22. Wang, SH: Answers to some open questions on fuzzy $\psi$-contractions in fuzzy metric spaces. Fuzzy Sets Syst. 222 115-119(2013)

10.1186/1687-1812-2014-153

Cite this article as: Wang et al.: New conditions on fuzzy coupled coincidence fixed point theorem. Fixed Point Theory and Applications 2014, 2014:153

\section{Submit your manuscript to a SpringerOpen ${ }^{\circ}$ journal and benefit from:}

- Convenient online submission

- Rigorous peer review

- Immediate publication on acceptance

- Open access: articles freely available online

- High visibility within the field

- Retaining the copyright to your article 